\title{
Participação dos nervos intercostais na inervação do diafragma de gatos (Felis catus, Linnaeus, 1758)
}

\author{
Innervation of diaphragm through intercostal nerves in cats (Felis catus, Linnaeus, 1758)
}

\author{
Marcelo Domingues de FARIA ${ }^{1}$; Carlos Eduardo SEYFERT² ; Karina Martinez GAGLIARDO ${ }^{3}$; Naianne \\ Kelly CLÉBIS ${ }^{4}$
}

\author{
'Área de Anatomia dos Animais Domésticos e Silvestres do Colegiado Acadêmico de Medicina Veterinária da Universidade \\ Federal do Vale do São Francisco, Petrolina - PE, Brasil \\ ${ }^{2}$ Departamento de Morfologia da Universidade Federal de Campina Grande, Cajazeiras - PB, Brasil \\ ${ }^{3}$ Médica Veterinária Autônoma \\ ${ }^{4}$ Departamento de Morfologia da Universidade Federal do Rio Grande do Norte, Natal - RN, Brasil
}

\begin{abstract}
Resumo
O objetivo do presente trabalho foi avaliar a inervação do músculo diafragma em gatos, proveniente dos nervos intercostais, contradizendo diversos autores que afirmam ser este músculo inervado apenas pelos ramos dos nervos frênicos direito e esquerdo. Foi observado que existe a frequência de nervos dispostos entre o $8^{\circ}$ e o $11^{\circ}$ espaços intercostais.
\end{abstract}

Palavras-chave: Gato. Diafragma. Nervos intercostais.

\begin{abstract}
The knowledge of organism's anatomy is essential to conduct any experiment or study with itself. Based on that, we decided to analyze and study in details the innervation of the diaphragm muscle from intercostal nerves in cats. It goes beyond other authors' analysis that describes only the innervation from phrenic nerves. Despite we have got a range of results, we observed a major frequency of eighth to tenth intercostal nerves going to diaphragm muscle.
\end{abstract}

Keywords: Cat. Diaphragm. Intercostal nerves.

\section{Introdução}

O diafragma é o principal músculo da inspiração, tratando-se de um largo músculo ímpar, que determina partição entre as cavidades torácica e abdominal, possuindo certa convexidade em sentido cranial, sendo recoberto cranialmente pela pleura e, caudalmente, pelo peritônio ${ }^{1}$. É formado por um centro tendíneo e por uma periferia muscular, que pode ser dividida em parte lombar, parte costal e parte esternal. Sabe-se que sua inervação é proveniente, fundamentalmente, dos nervos frênicos ${ }^{2,3,4,5,6,7,8,9,10,11,12,13}$.

No ser humano ${ }^{14,15,16}$, o diafragma recebe inervação do nervo frênico e também de muitas fibras delgadas procedentes dos seis últimos nervos intercostais, que distribuem-se exclusivamente na parte justacostal do diafragma, sendo a maior parte inervada pelo nervo frênico.
Cães, macacos e coelhos anestesiados tiveram seccionado o nervo frênico unilateralmente, ou de ambos os lados e, através de estímulos elétricos, foram avaliadas as respostas por meio de um oscilógrafo, demonstrando que o diafragma é inervado do $4^{\circ}$ ao $9^{\circ}$ par de nervos intercostais e em proporção maior pelo $8^{\circ}$ par de nervos intercostais. As fibras motoras não participavam da atividade respiratória, mas sim da resposta reflexa. O controle espinhal do diafragma inclui três grupos de fibras motoras, sendo duas

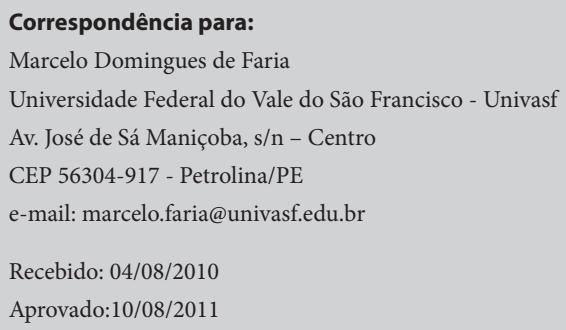


respiratórias: da $4^{\mathrm{a}}$ a $7^{\mathrm{a}}$ vértebra cervical (os nervos frênicos) e da $5^{\mathrm{a}}$ a $13^{\mathrm{a}}$ vértebra torácica (nervos intercostais $)^{17}$.

Em equinos ${ }^{18}$, os nervos intercostais $2,3,4,5$, e 6 emergem através dos espaços entre as cartilagens costais; e do $2^{\circ}$ ao $8^{\circ}$, emitem ramos musculares para o músculo transverso do tórax; os seguintes fornecem ramos musculares para a parte costal do diafragma. Os nervos intercostais constituem a principal inervação dos músculos intercostais externos e internos.

O diafragma de cães ${ }^{19}$ é inervado do $8^{\circ}$ ao $12^{\circ}$ par de nervos intercostais em $93,54 \%$ dos casos; e o $7^{\circ}$ nervo intercostal inerva o diafragma em 3,22\% dos casos.

Em fetos de bovinos azebuados ${ }^{20}$, a inervação do diafragma por nervos intercostais varia do $7^{\circ}$ ao $12^{\circ}$ par de nervos intercostais (50\%), do $6^{\circ}$ ao $12^{\circ}$ par de nervos intercostais $(33,3 \%)$, do $6^{\circ}$ nervo intercostal do antímero esquerdo $(13,3 \%)$ e do $7^{\circ}$ nervo intercostal do antímero direito $(3,3 \%)$.

Diante do que fora supramencionado, observa-se que os nervos intercostais são responsáveis pela inervação dos músculos intercostais externos e internos, mas também do diafragma, sendo que, no presente trabalho teve-se o intuito de descrever tal inervação, valendo-se de cadáveres de felinos domésticos, oferecendo subsídios técnicos anatômicos aos profissionais envolvidos com a clínica e cirurgia torácica destes animais.

\section{Material e Método}

Para realização do presente trabalho, foram utilizados 30 animais da espécie felina, sem raça defini$\mathrm{da}$, adultos de diferentes idades, sendo 15 machos e 15 fêmeas, sem sinais de doenças respiratórias, fornecidos em estado de óbito pelo Centro de Controle de Zoonoses (CCZ) da Secretaria Municipal de Saúde do Município de São Paulo e conduzidos ao Laboratório de Anatomia dos Animais Domésticos e Silvestres da Faculdade de Medicina Veterinária e Zootecnia da Universidade de São Paulo

\begin{tabular}{|c|c|c|c|}
\hline Animal & Sexo & NICD & NICE \\
\hline 01 & Macho & 9,10 e 11 & 9,10 e 11 \\
\hline 02 & Fêmea & 9,10 e 11 & 9,10, e 11 \\
\hline 03 & Macho & $8,9,10$ e 11 & 9,10 e 11 \\
\hline 04 & Fêmea & 8,9 e 10 & 8,9 e 10 \\
\hline 05 & Macho & 11 e 12 & 10,11 e 12 \\
\hline 06 & Fêmea & $8,9,10$ e 11 & $8,9,10$ e 11 \\
\hline 07 & Macho & 8,9 e 10 & 9,10 e 11 \\
\hline 08 & Fêmea & 7,8 e 10 & 8,9 e 10 \\
\hline 09 & Macho & $7,8,10$ e 11 & 7,8 e 9 \\
\hline 10 & Fêmea & 9 e 10 & 8 e 9 \\
\hline 11 & Macho & 9,10 e 11 & 9,10 e 11 \\
\hline 12 & Fêmea & 8,9 e 10 & 8,9 e 10 \\
\hline 13 & Macho & 9,10 e 11 & $8,9,10,11$ \\
\hline 14 & Fêmea & 10 e 11 & 10 e 11 \\
\hline 15 & Macho & 9,10 e 11 & 10 e 11 \\
\hline 16 & Fêmea & $8,9,10$ e 11 & 9,10 e 11 \\
\hline 17 & Macho & 10 e 11 & 9,10 e 11 \\
\hline 18 & Fêmea & 9,10 e 11 & $8,9,10$ e 11 \\
\hline 19 & Macho & $7,8,9$ e 10 & 8,9 e 10 \\
\hline 20 & Fêmea & 9 e 10 & 9 e 10 \\
\hline 21 & Macho & $8,9,10$ e 11 & 9,10 e 11 \\
\hline 22 & Fêmea & 10 e 11 & 9,10 e 11 \\
\hline 23 & Macho & 9,10 e 11 & $8,9,10$ e 11 \\
\hline 24 & Fêmea & 9,10 e 11 & 10 e 11 \\
\hline 25 & Macho & 9,10 e 11 & $8,9,10$ e 11 \\
\hline 26 & Fêmea & $8,9,10$ e 11 & 9,10 e 11 \\
\hline 27 & Macho & 10 e 11 & 10 e 11 \\
\hline 28 & Fêmea & 9,10 e 11 & $8,9,10$ e 11 \\
\hline 29 & Macho & 10 e 11 & 9,10 e 11 \\
\hline 30 & Fêmea & 10 e 11 & 10 e 11 \\
\hline
\end{tabular}

Quadro 1 - Participação dos nervos intercostais direitos (NICD) e esquerdos (NICE) inervando o diafragma de cada animal da espécie felina estudado - São Paulo - 2010

Tabela 1 - Participação percentual de ramos dos nervos intercostais na inervação do diafragma de gatos - São Paulo - 2010

\begin{tabular}{ccc} 
Nervo Intercostal & Antímero Direito & $\begin{array}{c}\text { Antímero } \\
\text { Esquerdo }\end{array}$ \\
\hline $7^{\circ}$ & $10 \%$ & $3,33 \%$ \\
\hline $8^{\circ}$ & $36,66 \%$ & $40 \%$ \\
\hline $9^{\circ}$ & $70 \%$ & $80 \%$ \\
\hline $10^{\circ}$ & $96,66 \%$ & $93,33 \%$ \\
\hline $11^{\circ}$ & $73,33 \%$ & $73,33 \%$ \\
\hline $12^{\circ}$ & $3,33 \%$ & $3,33 \%$ \\
\hline
\end{tabular}

(FMVZ-USP), onde tiveram canulada a artéria carótida comum esquerda, por onde se injetava solução aquosa de formaldeído a 10\%. Em seguida, os mesmos eram mergulhados em solução com a 
mesma formulação e concentração citada, por período não inferior a setenta e duas horas. Após fixação, rebatia-se o esterno através de incisão sobre as articulações costocondrais, a partir da sexta costela, em ambos os antímeros. Posteriormente, cada nervo intercostal era dissecado, conservando suas ramificações, enfatizando àquelas que seguiam em direção ao diafragma.

\section{Resultados}

Analisando o trajeto dos nervos intercostais, pôde-se observar que cada um percorria o sulco costal de sua respectiva costela, sobre sua margem caudal, sendo que foi observada inervação secundária do diafragma através de ramificações destes. Com base no quadro 1 e nas tabelas 1 e 2 , observou-se que existe predominância dos nervos intercostais 9, 10 e 11, mas outros nervos intercostais podem emitir ramos em direção ao diafragma, como é o caso do $7^{\circ}, 8^{\circ}$ e $12^{\circ}$.

\section{Discussão}

Analisando os nervos intercostais dos gatos estudados, pôde-se observar que cada um percorria o sulco costal na margem caudal de sua respectiva costela, corroborando com a descrição de diversos trata$\operatorname{dos}^{21,22}$, onde, seguindo seus trajetos, comprovava-se a veracidade do tema proposto - a participação na inervação do diafragma.

Contradizendo vários autores ${ }^{2,3,4,5,6,7,8,9,10,11,12,13}$, que descreveram o diafragma sendo inervado apenas pelos nervos frênicos, foi possível notar que o mús-

Tabela 2 - Percentual de gatos que recebem ramificações dos nervos intercostais, conforme sua sequência - São Paulo - 2010

\begin{tabular}{ccccc|c|c|c|c|c|c|c|c} 
N. I. & 7,8 e 9 & $\begin{array}{c}7,8,9 \\
\text { e } 10\end{array}$ & 7,8 e 10 & $\begin{array}{c}7,8,10 \\
\text { e } 11\end{array}$ & 8 e 9 & 8,9 e 10 & $\begin{array}{c}8,9,10 \\
\text { e } 11\end{array}$ & $\begin{array}{c}9 \text { e } 10 \\
9,10 \text { e } \\
11\end{array}$ & $\begin{array}{c}10 \text { e } 11 \\
\begin{array}{c}10,11 \\
\text { e } 12\end{array}\end{array} \begin{array}{c}11 \\
\text { e } 12\end{array}$ \\
\hline A. D. & 0 & $3,33 \%$ & $3,33 \%$ & $3,33 \%$ & 0 & $10 \%$ & $16,65 \%$ & $6,66 \%$ & $33,33 \%$ & $20 \%$ & 0 & $3,33 \%$ \\
\hline A. E. & $3,33 \%$ & 0 & 0 & 0 & $3,33 \%$ & $13,33 \%$ & $20 \%$ & $3,33 \%$ & $36,33 \%$ & $16,65 \%$ & $3,33 \%$ & 0 \\
\hline
\end{tabular}

Legenda: N.I. - nervos intercostais; A.D. - antímero direito; A.E. - antímero esquerdo
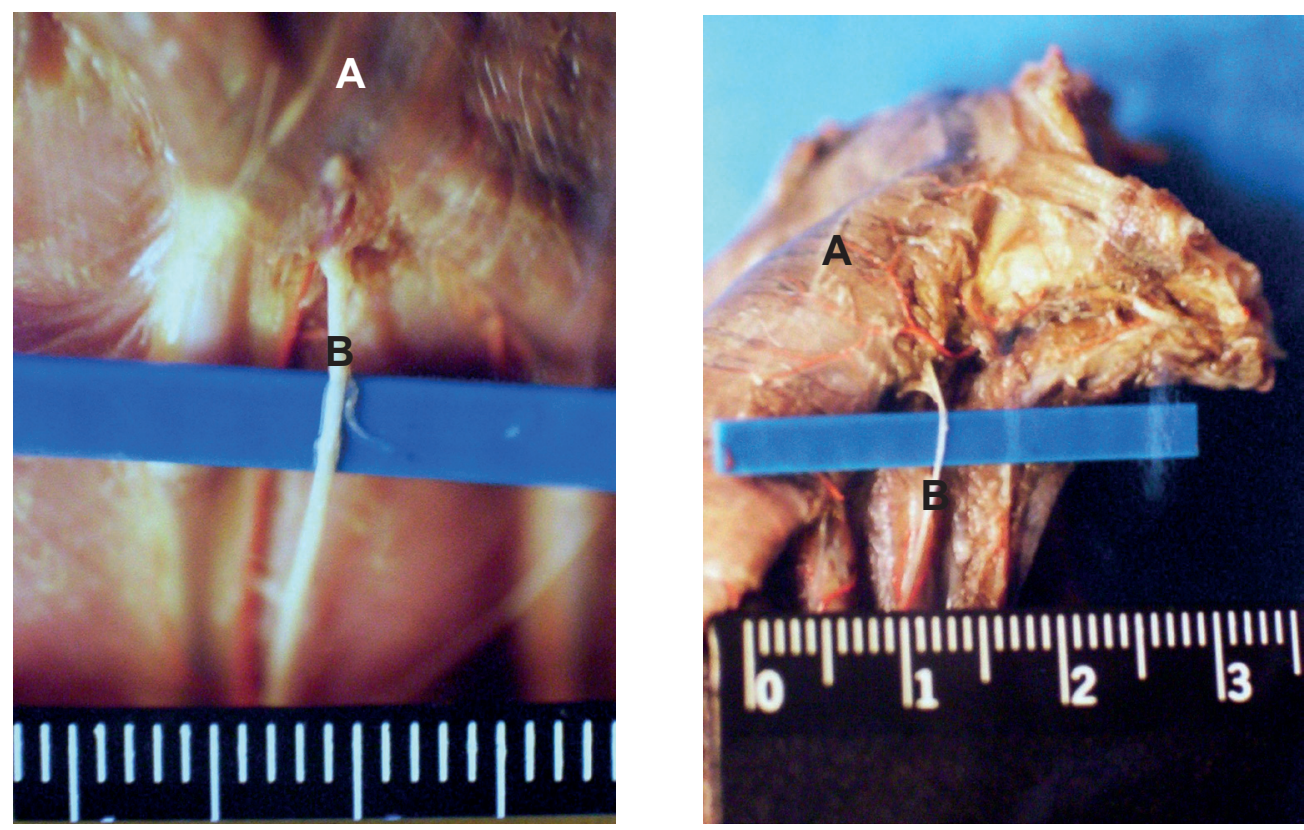

Figura 1 - Fotografias mostrando inervação do diafragma de gato (A) por ramo oriundo de nervo intercostal (B) - São Paulo - 2010 
culo possui inervações secundárias provenientes dos nervos intercostais (Figura 1). Contudo, tornou-se evidente a confirmação de outros autores, que descreveram em cadáveres humanos ${ }^{14,15,16}$, e outros, estudando outras espécies de animais ${ }^{17,18,19,20}$, que observaram a presença de fibras provenientes de nervos intercostais seguindo em direção ao músculo diafragmático.

\section{Referências}

1.SISSON, S. Diafragma. In: GETTY, R. Sisson/Grossman: anatomia dos animais domésticos. 5. ed. Rio de Janeiro: Interamericana, 1981. v. 1, p. 376-379.

2. BERTELLI, D. Contributo alla anatomia del diaframma nei carnivori. Monitore Zoologico Italiano, v. 1, n. 9-10, p. 211$215,1894$.

3. BERTELLI, D. Ricerche sulla morfologia del musculo diaframma nei mammiferi. Archives of Science and Medicine, v. 19, n. 4 , p. 381-436, 1895.

4. ZIMMERL, V. Sistemas nervoso. In: BOSSI, V.; CARADONNA, G. B.; SPAMPANI, G.; VARALDI, L.; ZIMMERL, V. Tratato di anatomia veterinária. Milano: Casa Editrice Dottor Francesco Vallardi, 1909. v. 2, p. 255-257.

5. BERTELLI, D. Distribuzione dei nervi frenice nei diaframma nei mammiferi. Archivio Italiano di Anatomia e di Embriologia, Firenze, v. 32, n. 1, p. 110-148, 1933.

6. FONTES, V. Notes anatomo physiologiques sur l'étude deu muscle diaphragm. Arquivo de Anatomia e Antropologia, v. 17 , n. 7, p. 34-36, 1934

7.BRUNI, A. C.; ZIMMERL, V. Anatomia degli animali domestici. Milano: Casa Editrice Dottor Francesco Vallardi, 1947. v. 2, p. 553-554.

8. CONDE, R. Estudo anatômico sobre a distribuição dos nervos frênicos no músculo diafragma de Canis familiaris. Arquivo da Escola de Veterinária da Universidade Federal de Minas, v. 10, n. 3, p. 329-365, 1957.

9. GONZALEZ. Y.; GARCIA, J.; GONZALEZ-ALVARES, R. Anatomia comparada de los animales domésticos. 7. ed. Madrid: Canalez, 1961. p. 800-801.

10.SCHWARZE, E.; SCHRÖDER, L. Compendio de anatomia veterinária. Zaragoza: Acribia, 1970. v. 2, p. 66-67.

11.EVANS, H.; DE LAHUNTA, A. Disseccion del perro. México: Interamericana, 1972. p. 594-595.

\section{Conclusões}

O diafragma de gatos, além de ser inervado pelos nervos frênicos, recebe ramos provenientes dos nervos intercostais, onde a maior constância acontece com os nervos intercostais 9, 10 e 11, mas o músculo diafragmático pode receber, também, fibras nervosas provenientes dos nervos intercostais 7,8 e 12 .

12.EVANS, H. E.; CHRISTENSEN, G. C. Miller's anatomy of the dog. 2. ed. Philadelphia: W.B. Saunders Company, 1979. p. $976-978$.

13. ROMER, A. S.; PARSONS, T. S. Anatomia comparada dos vertebrados. São Paulo: Atheneu, 1985. p. 256-262.

14. TESTUT, L. Trité de anatomie humanie. Paris: Octave Doin et Fils Ed., 1911. v. 1, p. 896-897.

15.WILLIAMS, P. L.; WARWICK, R.; DYSON, M.; BANNISTER, L. H. Gray anatomia. 37. ed. Rio de Janeiro: Guanabara Koogan, 1995. v.1, p. 781-782.

16.LOCCHI, R. Observações sobre o Musculus diaphragma no Bradypus tridactylus. Annaes da Faculdade de Medicina de São Paulo, v. 6, n. 6, p. 03-23, 1932.

17.ROSENBLUETH, A.; ALANIS, J.; PILAR, G. The accessory motor innervation of the diaphragm. Archives Internationales de Physiologie et de Biochimie, v. 69, n. 7, p. 19-25, 1961.

18. GHOSHAL, N. G. Nervos espinhias. In: GETTY, R. Sisson/ Grossman: anatomia dos animais domésticos. 5. ed. Rio de Janeiro: Interamericana, 1981. v. 1, p. 632.

19. MELO, A. P. F.; SOUZA, W. M.; MIGLINO, M. A. Branches of the intercostal nerves supplyng the diaphragm in dogs. Brazilian Journal of Morphological Sciences, v. 16, n. 1, p. 61-63, 1999.

20. OlIVEIRA, H. F. de; FARIA, M. D. de; MELO, A. P. F.; FERRAZ, R. H. S. Estudo anatômico sobre a participação dos nervos intercostais na inervação do diafragma em fetos de bovinos azebuados. Veterinária Notícias, Uberlândia, v. 7, n. 2, p. 23-26, 2001.

21.GETTY, R. Costelas. In: GETTY. R. Sisson/Grossman: anatomia dos animais domésticos. 5. ed. Rio de Janeiro: Interamericana, 1981. v. 1, p. 25.

22.DYCE, R. M.; SACH, W. O.; WENSING, C. J. G. Tratado de anatomia veterinária. Rio de Janeiro: Guanabara Koogan, 1990. p. 217. 